\title{
Metabolic acidosis in medical intensive care unit with indicators and their prognostic value- A prospective observational study
}

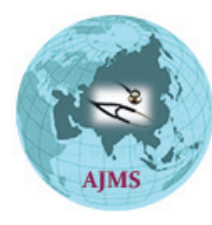

\author{
Prem Amalraj', Arun Kumar Narayanan', Satish Balan², Mathew Thomas ${ }^{3}$ \\ ${ }^{1}$ Resident, ${ }^{2}$ Consultant, Department of Nephrology, Kerala Institute of Medical Sciences, ${ }^{3}$ Consultant, Department of \\ General Medicine, Kerala Institute of Medical Sciences, Anayara, Thiruvananthapuram, Kerala, India
}

\section{A B S T R A C T}

Background: Metabolic acidosis is a common abnormality in the intensive care unit. There has recently been a surge of interest in nontraditional approaches to the analysis of acid base disorders. Aims and Objectives: This study was undertaken to compare the application of the physicochemical method of Stewart and the traditional Henderson-Hasselbach equation with correction for albumin in quantification of acid base disorders. Materials and Methods: All patients with metabolic acidosis admitted to the ICU as defined by a base deficit of $>2.5$ were included in the study. The APACHE II score was calculated at admission and the predicted mortality was defined. The acid base disorders were quantified by the traditional approach with anion gap correction for serum albumin as well as by the Stewart method with calculation of the strong anion gap acidosis. Results: One-hundred forty patients were included in the study of which $58 \%$ were males. In 125 subjects (89\%) acidosis was discovered by the Stewart method. The traditional method detected increased anion gap in 109 subjects (78\%) but this increased to 124 (88.5\%) when corrected for albumin. Both the strong ion gap (SIG) and the albumin corrected anion gap correlated strongly. Serum lactate levels and SIG predicted mortality as did albumin corrected anion gap. Conclusion: Albumin correction of the anion gap correlates well with acidosis as discovered by the SIG and therefore should be used in the ICUs rather than the traditional anion gap. With this modification, we can thus depend on the application of the intuitive traditional method rather than the more difficult to apply Stewart method for analysis of the acid base abnormalities in the ICU.

Key words: Anion gap, Henderson-hasselbach, Strong ion gap, Stewart model

\section{Website:}

http://nepjol.info/index.php/AJMS DOI: 10.3126/ajms.v8i3.16500

E-ISSN: 2091-0576

P-ISSN: 2467-9100

\section{INTRODUCTION}

Metabolic acidosis is one of the commonest disorders, among critically ill patients, faced by every clinician and intensivist on a day to day basis. It is associated with high morbidity and mortality irrespective of etiology.

Acid base analysis plays a very vital role in an intensive care unit. Metabolic acidosis may contribute to the morbidity and mortality associated with shock, although it may also have some protective effects in milder form. ${ }^{1}$
Abnormalities identified by various methods (strong ion gap (SIG), AG, lactic acidosis) appears to be more common in critically ill patients and are associated with increased mortality especially when it occurs early in the course of critical illness. ${ }^{2}$

Certain types of metabolic acidosis are strong independent predictors of mortality in critically ill patients and should be monitored in intensive care units. ${ }^{2}$

Lactic acidosis is commonly associated with mortality and hence Serum lactate is considered as an prognostic indicator of illness severity. ${ }^{3-5}$ 
The history of arterial blood gas analysis goes back over more than forty years. The relationship between base excess (BE), anion gap, hyperchloraemia, 'unmeasured' strong anions, and mortality is still unclear and controversy persists till date. The optimal assessment of the underlying mechanism is unknown.

The traditional anion gap, $\left(\mathrm{Na}^{+}+\mathrm{K}^{+}\right)-\left(\mathrm{Cl}^{-}+\mathrm{HCO}_{3}^{-}\right)$, does not account for the effect of weak acids, mostly albumin, which is commonly abnormal in critical illness.

Despite previous studies showing that neither base deficit nor anion gap are effective at discriminating between the presence or absence of hyperlactatemia, ${ }^{6-10}$ there persists the commonly held belief that normal anion gap or the absence of base deficit rules out the presence of hyperlactatemia.

Various indices like anion gap corrected for albumin, lactate, phosphate and base excess of unmeasured anions (Fencl-Stewart) were evaluated in clinical assessment of metabolic acidosis to ascertain their prognostic value. The conclusions among studies are not yet clear. ${ }^{11-13}$

Strong ion Gap (SIG) has been shown to be better than blood lactate, $\mathrm{pH}$, or injury severity scores in trauma patients and pediatric surgery patients as a predictor of mortality. ${ }^{14}$ At the bedside, both the apparent and effective SID can be calculated and used to determine the strong ion gap (SIG), which can then be used in a manner similar to anion gap.

The benefits of the SIG rests in its detection of otherwise unidentified anions in plasma whenever the serum total protein, albumin, and phosphate concentrations are markedly abnormal. ${ }^{15}$ SIG can be valuable in clinical settings or research studies investigating acid-base balance and help provide an understanding of acid-base properties of administered intravenous fluids. ${ }^{16,17}$

\section{AIMS AND OBJECTIVES}

Studies pertaining to acid base disorders in Indian journals are meager. Metabolic acidosis is associated with high morbidity and mortality irrespective of aetiology.

Rivers et al, ${ }^{14}$ utilized hypotension and elevated serum lactate levels to identify patients in shock and demonstrated that emergency department patients with presumed sepsis and a serum lactate level of $\geq 4.0 \mathrm{mmol} / \mathrm{L}$ and $/$ or frank hypotension are at a significant risk of death (38-59\% mortality).

This false belief was probably the reason that measurement of serum lactate was not considered a part of standard admission battery of laboratory tests. The other reason would be the affordability issue in this part of the world.

Some studies have suggested an independent association between low pH or standard base excess (SBE) and mortality ${ }^{11}$ whereas others have not. ${ }^{12}$

Park et al, ${ }^{13}$ showed that the use of standard base excess (SBE) with a cut off value of $<-2.0$ was able to detect $100 \%$ of measures with metabolic acidosis.

Our intention was to detect suspected clinical cases of metabolic acidosis, and to include those with a base excess cut off value $<-2.5$. And these groups were analyzed by various bedside metabolic acid-base indices and their relationship to lactate concentrations and outcomes in form of survival were noted. The various metabolic acid-base indices used to detect the unmeasured ions were anion gap (traditional method), strong ion gap (Stewart's), anion gap corrected for albumin and lactate (ACAG, ALCAG) and base excess of unmeasured anion (Fencl-Stewart method). Their relationships with each other were also noted.

To summarize, the study objectives are as follows:

1. To quantify acid base disorders according to the underlying mechanism of metabolic acidosis.

2. To compare the traditional and physicochemical methods of quantifying metabolic acidosis in patients admitted to an ICU among survivors and nonsurvivors.

3. To compare these variable's predictive value in terms of ICU mortality with serum lactate levels and APACHE II score.

We hope this study would be a refresher to all the clinicians and intensivists in India.

\section{MATERIALS AND METHODS}

All patients with suspected cases of metabolic acidosis admitted in the medical ICU. Approval for the study was obtained from the Ethics Review Board of Kerala Institute of Medical Sciences, Anayara, Thiruvananthapuram.

\section{Sampling}

Arterial blood-gas samples were taken anaerobically and lactate samples were analyzed at the best without significant delay. APACHE II scoring and predicted risk of mortality ${ }^{18,19}$ was calculated on admission. Electrolytes, BUN, serum Creatinine and serum albumin were measured in plasma. Table 1 provides a summary of measurement methodology. Sample size calculation was done as per the below mentioned formula. 


\begin{tabular}{lc} 
Table 1: Epidemiological, clinical and outcome \\
variables \\
\hline No. of cases & 140 \\
Age (in years) & $55 \pm 17$ \\
Gender, \%male & $54 \%$ \\
APACHE II on admission & $15 \pm 6$ \\
APACHE II, Mortality risk (\%) & $24 \pm 16$ \\
Admission type (\%) & \\
Sepsis & 47 \\
Gastrointestinal & 25 \\
Respiratory & 19 \\
Renal & 10 \\
Endocrine/Metabolic & 8 \\
Neurological & 7 \\
Hematological & 6 \\
Genitourinary & 5 \\
Malignancy & 3 \\
Overdosage/toxins & 3 \\
Miscellaneous & 7 \\
\hline
\end{tabular}

$\mathrm{N}=\left(\mathrm{Z} 2 \_\mathrm{x} \mathrm{p} \times \mathrm{q}\right) / \mathrm{d} 2$

Where $\mathrm{p}$ - prevalence of acidosis among those admitted in the ICU of

KIMS hospital $=0.80$

$Z \alpha=1.96$ for $\alpha=0.05$

$\mathrm{d}($ precision $)=10 \%$ of the prevalence $=0.08$

$\mathrm{N}=\left\{(1.96)^{2} \times 0.8 \times 0.2\right\} /(0.08)^{2}=96 \sim 100$

Sample size was also comparable based on several similar studies. $^{20}$

\section{Period of Study}

From Sept 12008 to Feb 2009

\section{Study Design}

Prospective, observational study.

\section{Setting}

Department of General Medicine at Kerala Institute of Medical Sciences, Thiruvananthapuram

\section{Inclusion Criteria}

1. Patients aged $\geq 18$

2. Either sex

3. Suspected case of metabolic acidosis with a SBE of $<-2.5$

\section{Exclusion Criteria}

1. Those with incomplete data.

2. Patients with primary respiratory components (Respiratory acidosis and alkalosis)

\section{Study Variables}

Patients who were included in the study had the following variables included:
1. Age

2. Sex

3. Reason for admission

4. Hemoglobin ( $\mathrm{Hb})$

5. Acid base variables $-\mathrm{pH}, \mathrm{pCO}_{2}, \mathrm{HCO}_{3}, \mathrm{SBE}$

6. Renal function tests BUN, S.Cr

7. Serum electrolytes $-\mathrm{Na}, \mathrm{K}, \mathrm{Cl}, \mathrm{Mg}, \mathrm{Ca}$, Phos

8. Serum Albumin

9. Serum Lactic acid (Fluoride)

\section{Outcome Variables}

1. Corrected serum anion gap for albumin

2. Corrected serum anion gap for albumin, lactate and phosphate

3. SID apparent (SIDa) and effective (SIDe)

4. Strong ion gap (SIG)

5. APACHE score

\section{Measurements and Calculations}

On admission, demographic data (age, gender) were recorded. Acute Physiology and Chronic Health Evaluation (APACHE) II score and predicted mortality rate 28, 29 were calculated on admission. All samples were analyzed in the hospital's main laboratory (cobas ${ }^{\circledR} 6000$ analyzer series; Roche Diagnostics Limited, Roche Diagnostics GmbH, Mannheim, Germany). Serum samples were collected in a serum separator tube and sent to the central laboratory for processing.

Blood gas samples were collected in a heparin syringe and arterial blood gas analyzed. Blood gas analysis included $\mathrm{pH}$, partial arterial $\mathrm{CO}_{2}$ tension, base deficit (SBE) and standard bicarbonate value (SB). $\mathrm{Na}+, \mathrm{K}+$, and $\mathrm{Cl}$ - were measured in the laboratory with the use of an indirect ion-selective electrode technique. Albumin was measured with a bromocresol dye colorimetric technique, $\mathrm{Mg}^{2+}$ by a chlorophosphonazo method, phosphate by a phosphomolybdate complex colorimetric technique, and $\mathrm{Ca}^{2+}$ by an ortho-cresolphthalein complex method. Lactate was measured with lactate oxidase peroxidase (LOPOD) complex.

The subjects were studied in three parts: first part comprised of comparisons of mean of the metabolic variables between survivors and non-survivors, by independent-samples' $t$ ' test assuming unequal variances. Also correlations between various metabolic parameters (AG, BE and SIG) within the group was studied.

\section{RESULTS}

One hundred and forty (140) patients were included. Their epidemiologic, clinical, and outcome variables are 
shown in the Table 1. Most of the patients were admitted to ICU directly from the emergency room and a few were admission in ICU from the wards/rooms (inpatients).

We were able to demonstrate a significant correlation between survival and albumin levels Table 2. In our study we had found that hypoalbuminemia (serum albumin $<3.5 \mathrm{~g} / \mathrm{dl}$ ) were present in 110/140 (78.6\%) of all patients and $24 / 26(92.3 \%)$ of those who had died. Hypoalbuminemia as a predictor of mortality with a RR of 3.3 (95\% CI.,819 - 13.0), PPV 21.8\%, NPV $93.3 \%$.

The Arterial acid base variables in the present study is shown in Table 3 among the measured and the derived variable serum albumin was $3.0 \pm 0.6 \mathrm{~g} / \mathrm{dl} \&$ derived

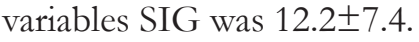

\begin{tabular}{|c|c|c|}
\hline Correlations & Albumin (g/dl) & Survival \\
\hline \multicolumn{3}{|l|}{ Albumin (g/dl) } \\
\hline Pearson correlation & 1 & $0.231^{* *}$ \\
\hline Sig. (2-tailed) & & 0.006 \\
\hline $\begin{array}{l}\text { Sum of squares and } \\
\text { cross-products }\end{array}$ & 50.661 & 7.576 \\
\hline Covariance & 0.364 & 0.055 \\
\hline $\mathrm{N}$ & 140 & 140 \\
\hline \multicolumn{3}{|l|}{ Survival } \\
\hline Pearson correlation & $0.231^{* *}$ & 1 \\
\hline Sig. (2-tailed) & 0.006 & \\
\hline $\begin{array}{l}\text { Sum of squares and } \\
\text { cross-products }\end{array}$ & 7.576 & 21.171 \\
\hline Covariance & 0.055 & 0.152 \\
\hline $\mathrm{N}$ & 140 & 140 \\
\hline
\end{tabular}

\section{Table 3: Arterial acid base variables}

\begin{tabular}{|c|c|c|}
\hline & $\begin{array}{c}\text { Normal } \\
\text { (our lab) }\end{array}$ & All cases $(n=140$ \\
\hline \multicolumn{3}{|l|}{ Measured variables } \\
\hline $\mathrm{Na}^{+}, \mathrm{meq} / \mathrm{L}$ & $136-145$ & $132 \pm 9$ \\
\hline $\mathrm{K}^{+}, \mathrm{meg} / \mathrm{L}$ & $3.5-5.1$ & $4.2 \pm 1.0$ \\
\hline $\mathrm{Ca}^{2+}, \mathrm{mg} / \mathrm{dL}$ & $8.8-10.2$ & $8.2 \pm 1.1$ \\
\hline $\mathrm{Mg}^{2+}, \mathrm{mg} / \mathrm{dL}$ & $1.7-2.55$ & $2.1 \pm 0.5$ \\
\hline $\mathrm{Cl}^{-}, \mathrm{mmol} / \mathrm{L}$ & $98-107$ & $98 \pm 8.6$ \\
\hline $\mathrm{Pi}-, \mathrm{mmol} / \mathrm{L}$ & $2.7-4.5$ & $3.7 \pm 2.2$ \\
\hline Albumin, $\mathrm{g} / \mathrm{dL}$ & $3.5-5.2$ & $3.0 \pm 0.6$ \\
\hline $\mathrm{pH}$ & $7.35-7.45$ & $7.33 \pm 0.1$ \\
\hline $\mathrm{pCO}_{2}, \mathrm{mmHg}$ & $35-45$ & $27.8 \pm 9.5$ \\
\hline Lactate, $\mathrm{mmol} / \mathrm{L}$ & $0-2$ & $4.07 \pm 3.1$ \\
\hline \multicolumn{3}{|l|}{ Derived variables, $\mathrm{mmol} / \mathrm{L}$} \\
\hline $\mathrm{HCO}^{3-}$ & $22-28$ & $15.8 \pm 5$ \\
\hline$A G_{\text {observed }}$ & $12-17$ & $22.2 \pm 7.6$ \\
\hline$A G^{\text {osserved }}$ & $12-17$ & $24.6 \pm 7.5$ \\
\hline $\mathrm{BE}$ & -2 to +2 & $-9.2 \pm 5.1$ \\
\hline BEua (Fencl-Stewart) & -2 to +2 & $-9.4 \pm 8.0$ \\
\hline$S I D_{\text {apparent }}$ & $40 \pm 2$ & $37.7 \pm 6$ \\
\hline$S I G{ }^{\text {apparent }}$ & $2 \pm 2$ & $12.2 \pm 7.4$ \\
\hline
\end{tabular}

The characteristics of patients presented according to outcome in the present study are shown in Table 4 among the measured and the derived variable among survivors and non survivors. Lactate levels were low $3.7 \pm 2.8$ in survivors and 5.6 \pm 4 among non survivors which was statistically not significant. However among the derived variable APACHE score II was 14.6 \pm 5.9 among survivors and $45 \pm 16.8$ among non survivors.

Table 5 shows the measured and derived variables according to hyperlactatemia serum creatinine among the hyperlactatemia was $2.4 \pm 2.7$ and SIG was $11 \pm 6.5$.

Table 6 and Figure 1-6 shows the characterstics of Hyperlactatemia patients (serum lactate $>2 \mathrm{mmol} / \mathrm{L}$ ) were present in 105 patients $(75 \%)$. Hyperlactatemia was severe (serum lactate $>5 \mathrm{mmol} / \mathrm{L}$ ) in 36 patients $(25 \%)$. Hypoalbuminemia was present in 101 patients $(72 \%)$. One-hundred thirty patients $(92.8 \%)$ had low serum bicarbonate level. With Stewart method metabolic acid base alterations were detected in 125 patients (89\%). Of which 109 patients (78\%) were cases of metabolic acidosis

\begin{tabular}{|c|c|c|c|}
\hline & $\begin{array}{c}\text { Survivors } \\
(n=114)\end{array}$ & $\begin{array}{c}\text { Non-survivors } \\
(n=26)\end{array}$ & $P$ value \\
\hline \multicolumn{4}{|l|}{ Measured variables } \\
\hline Age & $54.8 \pm 17.3$ & $56.5 \pm 17.6$ & 0.64 \\
\hline $\mathrm{Hb}(\mathrm{g} / \mathrm{dl})$ & $11.6 \pm 2.4$ & $11.2 \pm 3.6$ & 0.59 \\
\hline PCV (\%) & $37 \pm 8$ & $36 \pm 15$ & 0.83 \\
\hline Total count (in 1000's) & $13 \pm 6$ & $17 \pm 10$ & 0.04 \\
\hline $\mathrm{Na}^{+}, \mathrm{meq} / \mathrm{L}$ & $133 \pm 8.3$ & $129 \pm 11.4$ & 0.10 \\
\hline $\mathrm{K}^{+}, \mathrm{meq} / \mathrm{L}$ & $4.3 \pm 1.1$ & $4.1 \pm 0.9$ & 0.52 \\
\hline $\mathrm{Ca}^{2+}, \mathrm{mg} / \mathrm{dL}$ & $8.2 \pm 1.1$ & $8.1 \pm 0.9$ & 0.65 \\
\hline $\mathrm{Mg}^{2+}, \mathrm{mg} / \mathrm{dL}$ & $1.8 \pm 0.3$ & $1.7 \pm 0.5$ & 0.75 \\
\hline $\mathrm{Cl}^{-}, \mathrm{mmol} / \mathrm{L}$ & $99.2 \pm 8$ & $96.3 \pm 11$ & 0.22 \\
\hline $\mathrm{P} \dot{r}, \mathrm{mmol} / \mathrm{L}$ & $3.5 \pm 1.6$ & $4.9 \pm 3.6$ & 0.003 \\
\hline Albumin, g/dL & $31.3 \pm 6$ & $27.8 \pm 6$ & 0.01 \\
\hline $\mathrm{pH}$ & $7.34 \pm 0.10$ & $7.28 \pm 0.13$ & 0.03 \\
\hline $\mathrm{pCO}_{2}, \mathrm{mmHg}$ & $27.3 \pm 7.8$ & $30 \pm 14.6$ & 0.37 \\
\hline Lactate, $\mathrm{mmol} / \mathrm{L}$ & $3.7 \pm 2.8$ & $5.6 \pm 4$ & 0.03 \\
\hline S.Creatinine, $\mathrm{mg} / \mathrm{dL}$ & $2 \pm 1.9$ & $4.6 \pm 13$ & 0.33 \\
\hline \multicolumn{4}{|l|}{ Derived variables, } \\
\hline $\mathrm{HCO}^{3-}$ & $16 \pm 4.3$ & $14.7 \pm 6.2$ & 0.33 \\
\hline$A G$ & $22.1 \pm 6.6$ & $22.1 \pm 10$ & 1.0 \\
\hline$A G_{\text {corrected }}^{\text {observed }}$ & $24.3 \pm 6.3$ & $25.2 \pm 10.4$ & 0.67 \\
\hline$A G{ }^{\text {corrected }}$ & $22.9 \pm 7.2$ & $19.6 \pm 8.5$ & 0.07 \\
\hline $\mathrm{BE}{ }^{\text {corrected (Lact\&allb) }}$ & $-8.6 \pm 4.6$ & $-11.4 \pm 6.4$ & 0.05 \\
\hline BEua (Fencl-Stewart) & $-8.9 \pm 6.9$ & $-11.6 \pm 11.3$ & 0.25 \\
\hline $\mathrm{SID}_{\text {apparent }}$ & $38.3 \pm 5.8$ & $35 \pm 6.5$ & 0.02 \\
\hline SID & $25.7 \pm 5$ & $24.6 \pm 6.7$ & 0.45 \\
\hline SIG & $12.6 \pm 6.9$ & $10.4 \pm 9.1$ & 0.25 \\
\hline SBENa & $-2.05 \pm 2.5$ & $-3.2 \pm 3.4$ & 0.10 \\
\hline SBEcl & $-2.3 \pm 5$ & $-2.4 \pm 6.5$ & 0.95 \\
\hline SBEalb & $30.6 \pm 13.1$ & $38.2 \pm 14$ & 0.01 \\
\hline SBElact & $-2.7 \pm 2.8$ & $-4.6 \pm 4$ & 0.02 \\
\hline SBEsig & $-32 \pm 12.8$ & $-39.4 \pm 16$ & 0.04 \\
\hline APACHE score II & $14.6 \pm 5.9$ & $23.2 \pm 5.2$ & 0.000 \\
\hline Predicted Mortality & $22.8 \pm 13.9$ & $45 \pm 16.8$ & 0.000 \\
\hline
\end{tabular}


detected by low SID. However, $109(78 \%)$ of these patients had increased anion gap and $124(88.5 \%)$ had increased albumin corrected anion gap. Consequently the use of albumin corrected anion gap among critically ill patients permitted the additional diagnosis of 15 patients with metabolic acidosis. SIG and albumin corrected AG strongly correlated and showed narrow $95 \%$ limits of agreement (0.77-0.95) in critically ill patients. The mean duration of stay $5.0 \pm 2.8$ days.

Among the non-survivors, $78.1 \%(8 / 26)$ of the deaths were attributed by base deficit due to unmeasured anions.

\begin{tabular}{|c|c|}
\hline & $\begin{array}{l}\text { Lactate level }>5 \mathrm{mmol} / \mathrm{L} \\
\qquad(\mathrm{n}=38)\end{array}$ \\
\hline \multicolumn{2}{|l|}{ Measured variables } \\
\hline Age & $59 \pm 14$ \\
\hline $\mathrm{Na}^{+}, \mathrm{meq} / \mathrm{L}$ & $132 \pm 9.9$ \\
\hline $\mathrm{K}^{+}, \mathrm{meq} / \mathrm{L}$ & $4.6 \pm 1.2$ \\
\hline $\mathrm{Mg}^{2+}, \mathrm{mg} / \mathrm{dL}$ & $1.7 \pm 0.4$ \\
\hline $\mathrm{Cl}^{-}, \mathrm{mmol} / \mathrm{L}$ & $97.8 \pm 9.4$ \\
\hline Albumin, $g / L$ & $4.4 \pm 2.5$ \\
\hline $\mathrm{pH}$ & $7.27 \pm 0.12$ \\
\hline $\mathrm{pCO}_{2}, \mathrm{mmHg}$ & $28.5 \pm 12.4$ \\
\hline Lactate, $\mathrm{mmol} / \mathrm{L}$ & $8.2 \pm 2.9$ \\
\hline Serum Creatinine, $\mathrm{mg} / \mathrm{dL}$ & $2.4 \pm 2.7$ \\
\hline \multicolumn{2}{|l|}{ Derived variables, } \\
\hline $\mathrm{HCO}^{3-}$ & $14.3 \pm 5$ \\
\hline$A G_{\text {observed }}$ & $24.6 \pm 7$ \\
\hline$A G_{\text {corrected }}$ & $27.3 \pm 6.7$ \\
\hline$A G_{\text {corrected (Lact\&alb) }}$ & $20 \pm 7.3$ \\
\hline $\mathrm{BE}^{\text {correcled (Lacidalo) }}$ & $-11.5 \pm 5.4$ \\
\hline \multicolumn{2}{|l|}{ BEua (Fencl-Stewart) } \\
\hline SID ${ }_{\text {apparent }}$ & $34.4 \pm 5.5$ \\
\hline SID & $23.5 \pm 5.4$ \\
\hline SIG & $11 \pm 6.5$ \\
\hline SBENa & $-2.3 \pm 2.9$ \\
\hline SBEcl & $-1.5 \pm 5.1$ \\
\hline SBEalb & $34.7 \pm 14.8$ \\
\hline SBElact & $-7.2 \pm 2.9$ \\
\hline SBEsig & $-35 \pm 15$ \\
\hline APACHE score II & $19.6 \pm 7.2$ \\
\hline Predicted Mortality & $35.3 \pm 20$ \\
\hline
\end{tabular}

Among the non-survivors, 42.3\% (11/26) of the deaths were attributed by hyperlactatemia (serum lactate $>5 \mathrm{mEq} / \mathrm{L})$.

\section{DISCUSSION}

One-hundred forty patients were included in our prospective observational study. On the basis of the mechanism of metabolic acidosis, we categorized them into hyperlactatemia/lactic acidosis (Serum lactate $>2.5 \mathrm{meq} / \mathrm{l}$ ), SIG acidosis (>5 meq/l), and hyperchloremic acidosis (as an entity which may not be explained by lactic acidosis or SIG acidosis)..$^{21,22}$

The physicochemical approach described by Stewart provides an accurate way of quantifying metabolic acidosis. There is a strong correlation between the SIG, the albumin- and lactate corrected anion gap. ${ }^{23}$ In our study we also demonstrated a strong correlation. Lactic acidosis and high SIG has been shown to be associated with adverse outcomes. $^{24-26}$

In our study, we noticed that $60.5 \%$ of survivors and $77 \%$ of non-survivors had an increased lactic acid level of $>2.5$ meq/1, and $89 \%$ of survivors and $77 \%$ of non survivors had SIG acidosis. Probably these results reflect the onadmission levels which no doubt will be elevated, albeit, there were no serial levels for comparison. ${ }^{27}$

Anion gap or the albumin corrected anion gap was insensitive in detecting hyperlactatemia $>2.5$ and ROC shows us that lower levels anion gap increases sensitivity in detecting hyperlactatemia.

Acute renal failure is defined as a creatinine value of $>150 \mu \mathrm{mol} / \mathrm{L} 32 .^{28,29}$ Our study had a total of 56 patients who had their serum creatinine levels above $150 \mu \mathrm{mol} / \mathrm{L}$. Out of the 26 patients who died, the majority of the cause of death was attributed by Sepsis (38.6\%), followed by gastrointestinal (35\%) (Mostly chronic liver disease).

Table 6: Correlation and logistic regression analysis for lactate

\begin{tabular}{lcccc}
\hline & Pearsons correlation & $\boldsymbol{P}$ value & Area under ROC curve (95\%Cl) & $\boldsymbol{P}$ value \\
\hline SBE & -0.328 & 0.000 & $0.682(0.57-0.78)$ & 0.001 \\
BEua & -0.321 & 0.000 & $0.676(0.58-0.77)$ & 0.001 \\
AG $_{\text {observed }}$ & 0.244 & 0.004 & $0.360(0.25-0.46)$ & 0.011 \\
AGalb $_{\text {AL }}$ & 0.282 & 0.001 & $0.329(0.22-0.43)$ & 0.002 \\
SIDa & 0.237 & 0.005 & $0.639(0.53-0.74)$ & 0.012 \\
SIDe & -0.408 & 0.000 & $0.737(0.64-0.83)$ & 0.000 \\
VanSlyke's Eq & -0.250 & 0.003 & $0.664(0.55-0.76)$ & 0.003 \\
Wooten's Eq & -0.288 & 0.001 & $0.672(0.56-0.77)$ & 0.002 \\
\hline
\end{tabular}

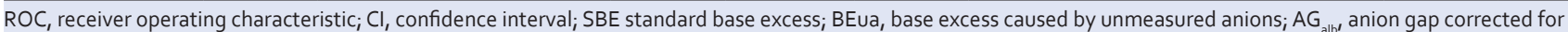
albumin; $\mathrm{AG}_{\mathrm{AL}}$, AG corrected for albumin and lactate; SIDe, strong ion difference effective; SIDa, strong ion difference apparent 


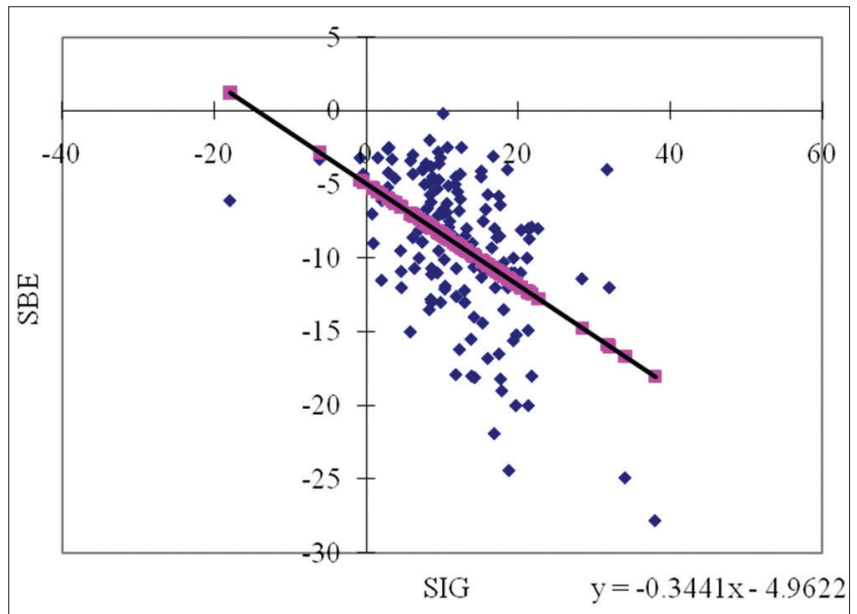

Figure 1: Regression analysis between SIG ( $\mathrm{mmol} / \mathrm{L})$ and BE $(\mathrm{mmol} / \mathrm{L})$

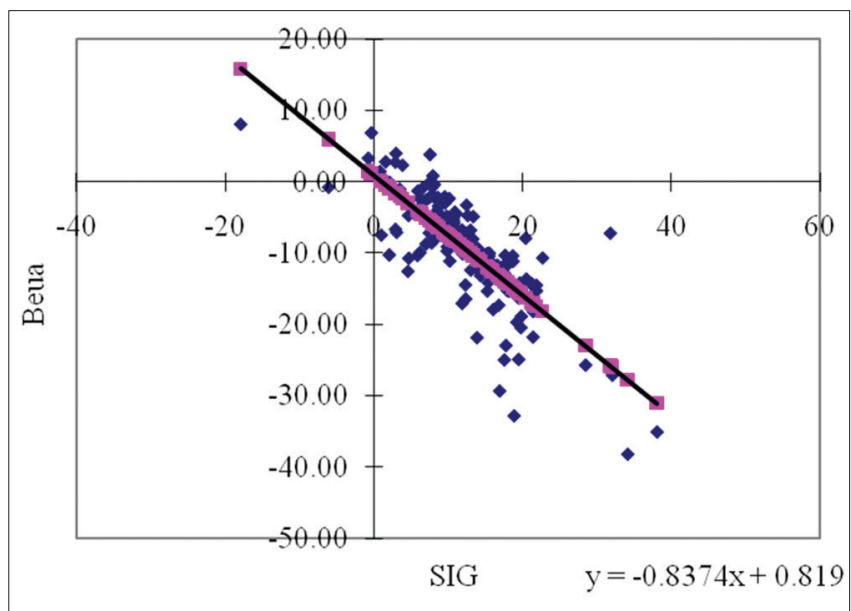

Figure 2: Regression analysis between SIG (mmol/L) and BEua $(\mathrm{mmol} / \mathrm{L})$

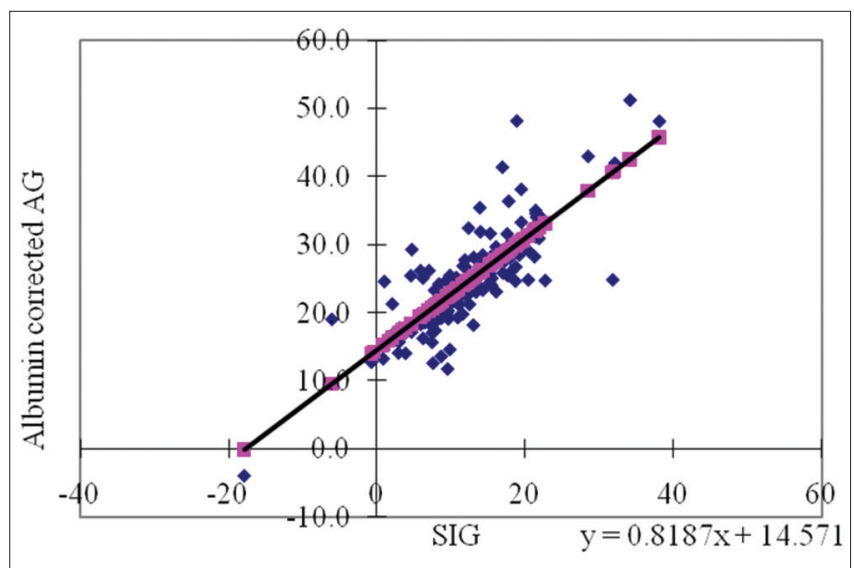

Figure 3: Regression analysis between albumin corrected anion gap $(\mathrm{mmol} / \mathrm{L})$ and $\mathrm{SIG}(\mathrm{mmol} / \mathrm{L})$

In a study among patients admitted in the ICU with acute asthmaticus, those who had lower arterial $\mathrm{pH}$ within $24 \mathrm{~h}$ of hospital admission were associated with increased mortality. ${ }^{30}$

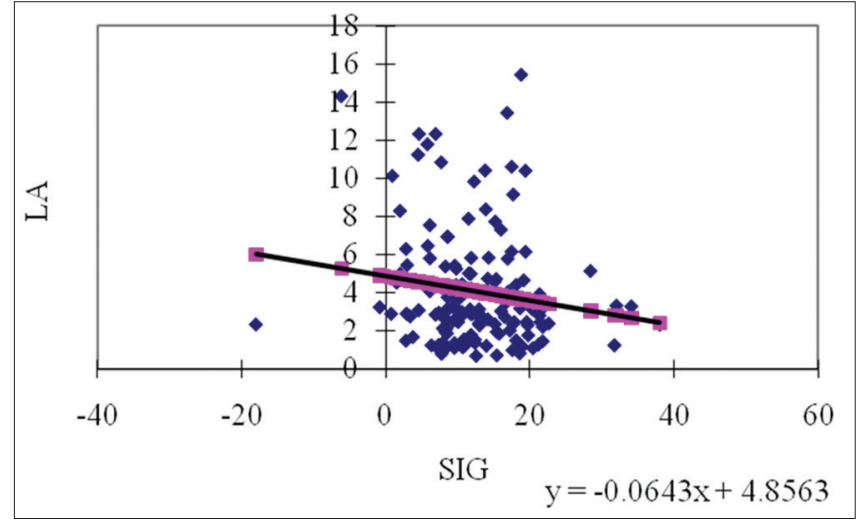

Figure 4: Regression analysis between Lactic acid (mmol/L) and SIG $(\mathrm{mmol} / \mathrm{L})$

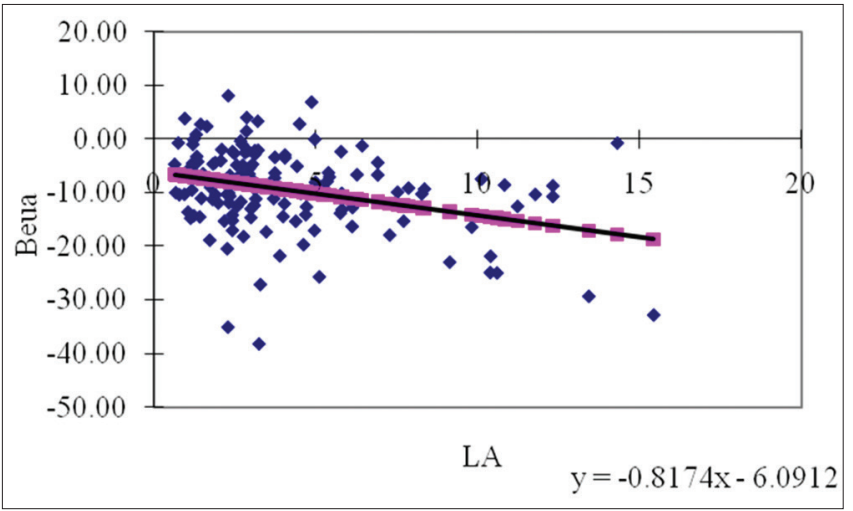

Figure 5: Regression between BEua (Fencl-Stewart method) and Lactic acid

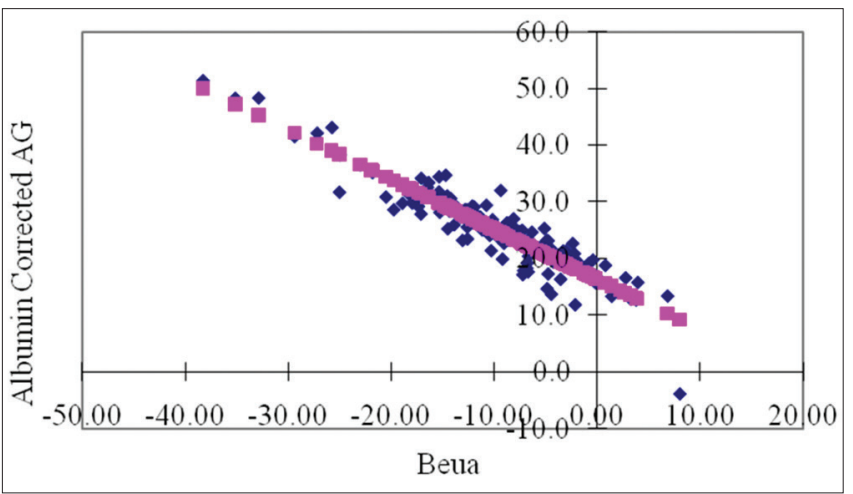

Figure 6: Regression between albumin corrected AG and BEua

Whereas several other studies had demonstrated that delay of academia recovery as opposed to initial $\mathrm{pH}$ value was associated with increased mortality in the ICU., ${ }^{31,32}$ In our study, we were able to demonstrate that $\mathrm{pH}$ was able to predict the risk of death with a RR of 2.94 (CI, 1.14-7.59) In our study we had found that hypoalbuminemia (serum albumin $<3.5 \mathrm{~g} / \mathrm{dl}$ ) were present in 101/140 $(72 \%)$ of all patients and 24/26 (92.3\%) of those who had died. Hypoalbuminemia as a predictor of mortality with a RR of 4.8 (95\% CI, $1.02-23.1)$, PPV $21.8 \%$, NPV 93.3\%. 
Length of stay in hospital and in ICU did not differ significantly between the different groups of metabolic acidosis. Hyperlactatemia (serum lactate $>2 \mathrm{mmol} / \mathrm{L}$ ) were present in 105 patients $(75 \%)$. Hyperlactatemia was severe (serum lactate $>5 \mathrm{mmol} / \mathrm{L}$ ) in 36 patients $(25 \%)$. One-hundred thirty patients $(92.8 \%)$ had low serum bicarbonate level. With Stewart method metabolic acid base alterations were detected in 125 patients (89\%). Of which 109 patients $(78 \%)$ were cases of metabolic acidosis detected by low SID. However, 109 (78\%) of these patients had increased anion gap and $124(88.5 \%)$ had increased albumin corrected anion gap. Consequently the use of albumin corrected anion gap among ${ }^{32}$ critically ill patients permitted the additional diagnosis of 15 patients with metabolic acidosis. SIG and albumin corrected AG strongly correlated and showed narrow $95 \%$ limits of agreement (0.77-0.95) in critically ill patients. The mean duration of stay $5.0 \pm 2.8$ days. Among the non-survivors, $15.4 \%$ $(4 / 26)$ of the deaths were attributed by hyperchloremia $(\mathrm{Cl}>110 \mathrm{meq} / \mathrm{L})$.

\section{Strengths of our Study}

- Studies pertaining to this type of acid base analysis is meager in India and we hope this could be a refresher for all clinicians.

- Understanding of complex acid-base disturbances and their mechanisms will lead to more targeted treatments of acid-base and electrolyte disorders especially in ICU/critically ill patients.

\section{Limitations}

Our study had a few limitations

- Serial lactate measurements would have let us to evaluate the prognostic value and access its risk of mortality.

\section{REFERENCES}

1. Vornov JJ, Thomas AG and Jo D. Protective effects of extracellular acidosis and blockade of sodium/hydrogen ion exchange during recovery from metabolic inhibition in neuronal tissue culture. J Neurochem 1996; 67(6):2379-2389.

2. Ronco C, Bellomo R and Kellum JA Acid-Base Disorders and Strong Ion Gap: Acute Kidney Injury. Contrib Nephrol. Basel, Karger, 2007;156;158-166.

3. Vitek V and Cowley RA: Blood lactate in the prognosis of various forms of shock. Ann Surg 1971; 173:308-313.

4. Bakker J, Coffernils M, Leon M, Gris P and Vincent JL. Blood lactate levels are superior to oxygen-derived variables in predicting outcome in human septic shock. Chest 1991; 99:956-962.

5. Davies AR, Bellomo R, Raman JS, Gutteridge GA and Buxton BF.:High lactate predicted the failure of intraaortic balloon pumping after cardiac surgery. Ann Thorac Surg 2001; 71:1415-1420.

6. Iberti TJ, Leibowitz AB, Papadakos PJ and Fischer EP: Low sensitivity of the anion gap as a screen to detect hyperlactatemia in critically ill patients. Crit Care Med 1990; 18:275-277.

7. Jeng JC, Jablonski K, Bridgeman A and Jordan MH. Serum lactate, not base deficit, rapidly predicts survival after major burns. Burns 2002; 28:161-166.

8. Levraut J, Bounatirou T, Ichai C, Ciais JF, Jambou P, Hechema R, et al. Reliability of anion gap as an indicator of blood lactate in critically ill patients. Intensive Care Med 1997; 23:417-422.

9. Mikulaschek A, Henry SM, Donovan R and Scalea TM: Serum lactate is not predicted by anion gap or base excess after trauma resuscitation. J Trauma 1996; 40:218-222.

10. Singh RN, Singh NC, Hutchison J and Moses GC. Lower anion gap increases sensitivity in predicting elevated lactate. Clin Intensive Care 1994; 5:221-224.

11. Smith I, Kumar P, Molloy S, Rhodes A, Newman PJ, Grounds RM, et al. Base excess and lactate as prognostic indicators for patients admitted to intensive care. Intensive Care Med 2001; 27:74-83.

12. Balasubramanyan N, Havens PL and Hoffman GM: Unmeasured anions identified by the Fencl-Stewart method predict mortality better than base excess, anion gap, and lactate in patients in the pediatric intensive care unit. Crit Care Med 1999; 27:1577-1581.

13. Park M, Taniguchi LU, Noritomi DT, Braga AL, Maciel AT and Cruz-Neto LM. Clinical utility of standard base excess in the diagnosis and interpretation of metabolic acidosis in critically ill patients. Brazilian Journal of Medical and Biological Research 2008; 41: 241-249.

14. Rivers E, Nguyen B, Havstad S, Ressler J, Muzzin A, Knoblich B, et al. Early goal-directed therapy in the treatment of severe sepsis and septic shock. N Engl J Med 2001; 345:1368-1377.

15. Davis JW, Kaups KL and Parks SN. Base Deficit Is Superior to $\mathrm{pH}$ in Evaluating Clearance of Acidosis after Traumatic Shock. The Journal of Trauma: Injury, Infection, and Critical Care 1998; 44(1):114-118.

16. Kiessling SG, Goebel J and Somers MJG. Tools for the diagnosis of renal disease, Pediatric Nephrology in the ICU. Springer 2008; 153-154.

17. Severinghaus JW. Acid-base balance controversy: case for standard-base excess as the measure of nonrespiratory acidbase imbalance. J Clin Monit 1991;7:276-277.

18. Gunnerson KJ. Clinical review: The meaning of acid-base abnormalities in the intensive care unit part I - epidemiology. Critical Care 2005; 9:508-516.

19. Kellum JA. Clinical review: Reunification of acid-base physiology. Critical Care 2005; 9:500-507.

20. Dunham CM, Siegel JH, Weireter L, Fabian M, Goodarzi S, Guadalupi $P$, et al. Oxygen debt and metabolic acidemia as quantitative predictors of mortality and the severity of the ischaemic insult in hemorrhagic shock. Crit Care Med 1991; 19:231-243.

21. Smith I, Kumar P, Molloy S, Rhodes A, Newman PJ, Grounds RM, et al.Base excess and lactate as prognostic indicators for patients admitted to intensive care. Intensive 2001; 27(1):74-83.

22. http://www.anzca.edu.au/resources/books-and- publications/ australasian-anaesthesia-2003/95\%20MORGAN.pdf

23. Kofstad J. Base excess: a historical review-has the calculation of base excess been more standardised the last 20 years? Clinica Chimica Acta 2001; 307(1-2):193-195.

24. Morris CG and Low J. Metabolic acidosis in the critically ill: Part 1. Classification and pathophysiology. Anaesthesia 2008; 63:294-301.

25. Reddy $\mathrm{P}$ and Mooradian AD. Clinical utility of anion gap in deciphering acid-base disorders. Int $\mathrm{J}$ Clin Pract 2009; 63(10):1516-1525. 
26. Figge $J$, Jabor $A$, Kazda $A$ and Fencl V. Anion gap and hypoalbuminemia. Crit Care Med 1998; 26:1807-1810.

27. Rocktaeschel J, Morimatsu H, Uchino $S$ and Bellomo R. Unmeasured anions in critically ill patients: can they predict mortality? Crit Care Med 2003; 31(8): 2244-2245.

28. Knaus WA, Draper EA, Wagner DP and Zimmerman JE. APACHE II: a severity of disease classification system. Crit Care Med 1985; 13: 818-829.

29. Moviat M, van Haren F, van der Hoeven H. Conventional or physicochemical approach in intensive care unit patients with metabolic acidosis. Crit Care 2003; 7:R41-R45.
30. Kaplan LJ and Kellum JA. Initial pH, base deficit, lactate, anion gap, strong ion difference, and strong ion gap predict outcome from major vascular injury. Crit Care Med 2004; 32:1120-1124.

31. Moviat M, Terpstra AM, Ruitenbeen W, Pickkers P, Kluijtmanset LAJ, van der Hoeven JG. Contribution of various metabolites to the "unmeasured anions" in critically ill patients with metabolic acidosis. Crit Care Med 2008;36(3):752-758.

32. Durward A, Skellet S, Mayer A, Taylor D, Tibby SM and Murdoch IA. The value of the chloride: sodium ratio in differentiating the aetiology of metabolic acidosis. Intensive Care Med 2001; 27:828-835.

Authors Contribution:

AKN and PAJ- Concept, collected data and design of the study, reviewed the literature, manuscript preparation and critical revision of the manuscript; MT and

SB-Conceptualized study, literature search, interpreted and review of study.

Orcid ID:

Dr. Prem Amalraj: (10) http://orcid.org/0000-0003-1253-3632

Dr. Arun Kumar.Narayanan: (D) http://orcid.org/0000-0001-5801-9415

Dr. Mathew Thomas: (i) http://orcid.org/0000-0002-4282-1523

Source of Support: None, Conflict of Interest: None. 